climate. The abundance of sunlight is a very favorable factor, a strong asset, in favor of our southern climate. This we see exemplified by the searcity of acute pneumonic tuberculosis in our southern states. Our house construction also forms an important item in the warfare against tuberculosis in the south, so also does our mode of living.

Therefore, as nature has been so kind as to give us such favorable climatic conditions, let us show in the future, by statistical reports of aggressively treated cases, that in our southern states we can, with aggressive treatment, promise the white plague sufferer as good results as those of any other locality.

\section{INDIVIDUALIZING THE TUBERCULOUS PATIENT.*}

By Lucius B. Morse, M.D., Hendersonville, N. C.

Physician in charge of Dr. Morse's Sanatorium.

The burden of this paper is to call attention to the all too common habit of generalizing the treatment of the tuberculous patient, and to emphasize the need of individualizing the care of such cases. There are several reasons why the treatment of these patients becomes general in its nature. First of all there has been an enormous amount of matter in the popular press regarding the treatment of pulmonary tuberculosis. The public is always on the alert for some short cut, some easily remembered phrase or formula, which, if followed, will bring about a speedy restoration to health. The average American newspaper reader possesses rather scant respect for minor details. The newspaper man's business consists largely in understanding what the public wants; as a result tuberculosis therapy has been reduced to a few general rules, and the cure rendered simple. The formula commonly put forward is the greatest possible amount of rest, fresh air and good food-all well enough so far as they go. Laymen and physicians alike very frequently look upon this generalization as being all-sufficient.

Another reason why the treatment of this grave disease becomes so commonly general rather than individualistic is the fact that many otherwise excellent physicians after a few months weary of the many details involved, they drift into routinism and in not a few instances the "cure" is turned over to the patient. What applies in this

\footnotetext{
*Read at the Sixth Annual Meeting of the Southern Medical Association. Jacksonville, Fla., November $12-14,1912$.
}

connection to tuberculosis applies in like manner to the treatment of many chronic ailments. With the acute disease it is different-the changes are rapid, and the attention and interest more easily held-each case being one of action. Not so with the chronic disease. The successful management of pulmonary tuberculosis demands sustained interest.

General formulae and principles are valuable only in so far as they constitute the foundation upon which is erected an elaborate and useful superstructure of details. There is probably no other disease wherein the supervision, regulation and control of the minutae of the patient's daily routine counts for so much as it does in chronic, pulmonary tuberculosis. Detailed management is waluable in all chronic diseases, but in relatively few of them do we have to confront constantly, month in and month out, the problem of toxemic infection.

I confidently believe that the most important duty of the man who is treating tuberculosis is the singling out and correction of the things that kill. By this I mean the infinite number and variety of little things that weigh in the balance against a cure from this treacherous disease, and, in the daily observation of the patient, the task of the physician here, as elsewhere in the practice of medicine, is to reason, not from cause to effect, but from effect back to a probable cause. It is exceedingly difficult at times to ascertain and correct the cause of some aggravation of symptoms, and yet this is a most essential thing to accomplish. A patient who is under any sort of control will rarely commit the graver types of indiscretions, so that real success in tuberculosis thereapy comes down to a nice regulation of the minor details.

Now, in this every person is a law unto himself. What is meat for one is another man's poisonevery patient must be individualized. General rules are valuable, but in regulating the life of each individual the execptions are most conspicuous; so much so, indeed, that one calls to mind the Frenchman's ejaculation concerning the rules for spelling English words, viz.: that it was exception, exception, exception!

Probably the explanation in part at least as to the reasons for good physicians tiring of tuberculosis, is lack of time on the one hand and opportunity on the other to supervise the details of the patient's daily life. A daily clinical chart of some sort which is kept by the patient or nurse is of great assistance. It can be of the loose leaf variety, in book form or in continuous rolls such as I have devised. The great value of a chart of 
this character is that it constitutes a compact, abriged, graphic, clinical, daily record of the patient, with the immense advantage that the phy. sician has the daily check on the case with the possibilities of a quick review. (See Figs. 1 and 2.)

It might not be amiss to call attention to some of the unusual, contradictory and otherwise interesting things that come up constantly in the man- member and teach this dictum to all such patients! "The cure lies largely within yourself." Doctor and patient alike must be co-partners in the fight. The two-hour temperature record might almost be called the physician's stock ticker.

How frequently do we see the half degree of temperature rise from a game of cards, writing a letter or even from reading. I knew one patient who invariably developed temperature from simply the

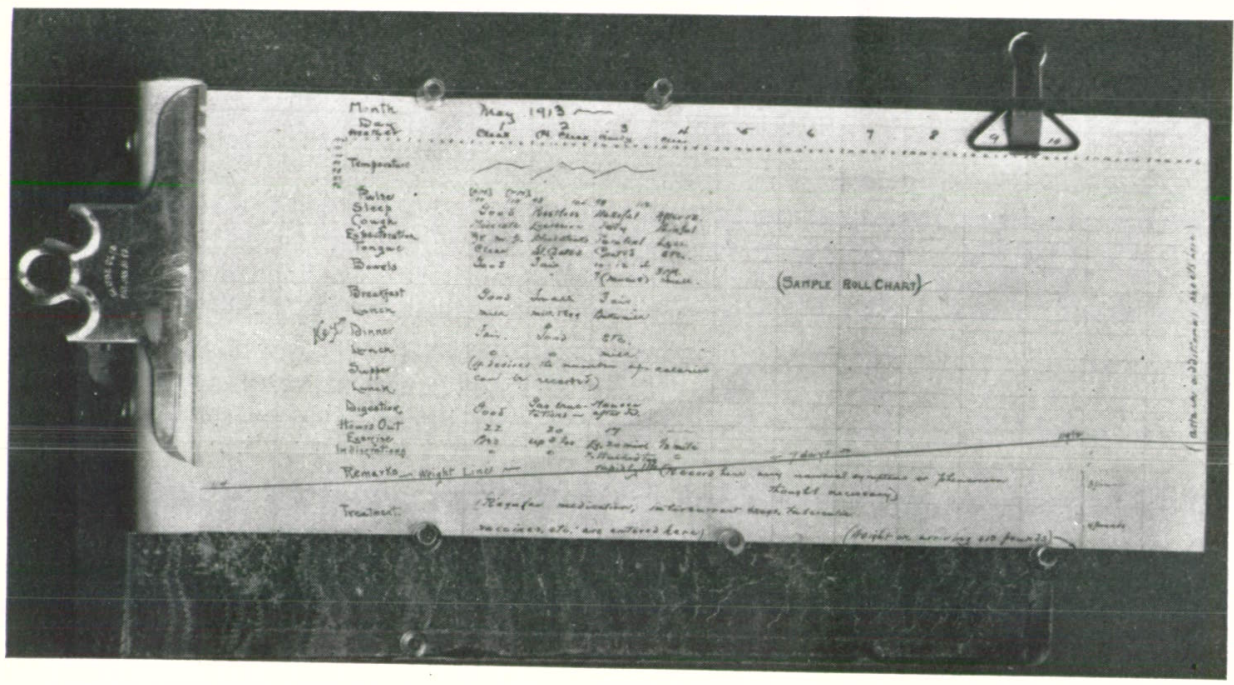

Fig. 1 - This chart is largely self - explanatory. The daily record is seen to be in vertical columns. tical columns, the tempera$\mathrm{t} u \mathrm{r} e$ a $\mathrm{n}$ d weight line is charted in, the latter once a week, the hor$r$ orenting $r$ e p r esenting pounds or mulpounds. Addipounds. Addi-
tional sheets are quickly attached by 11q. uid glue (Le Page's tubes). The whole chart is grad. chart is grad. upon $\quad$ rolled wooden rounds, and retained by the usual writing board.

agement of tuberculous patients to exemplify more succinctly the need of greater individualization. In the outset it must be remembered that the temperature curve is the physician's guide board. On its tracery can be read the minutest details affecting the patient's daily life. Herein we can see, step by step, the road along which our patient is traveling. All patients should take, read and record their own temperature. Do not be fear- reading of a newspaper. The same patient could walk two miles a day with no evidence of fever reaction. A physician was under my care for incipient closed tuberculosis. He was on fivemile daily exercise with never any reaction, but a few minutes of worry would invariably develop a degree of fever. Excessive cough is, of course, a common cause of febrile reaction and must, if possible, be controlled.

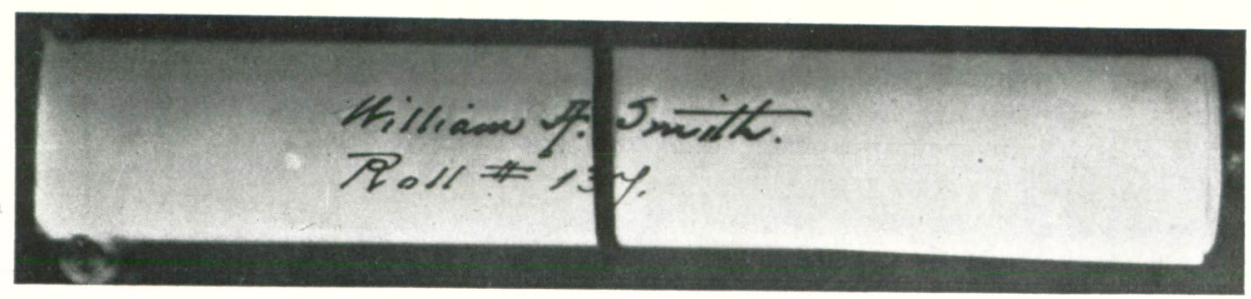

Fig. 2. Shows the completed roll ready for filing.

ful that your patient will form the "thermometer habit." If there is anything that is now proven, it is that patients are directly benefited by taking their own temperature. Only rarely do they become morbidly introspective. By and with the guidance of a physician it enables the patient to check up, to keep "tab" on himself, if you please. It makes him responsible for his every act. Re-
The care of the hair in women, and especially the washing of the hair, will cause some rise of temperature, I should say in every instance. I have seen blood streaked sputum simply from the act of washing the hair. The process is always a tiresome one in frail patients. Men almost as commonly have temperature, in greater or less degree, from the act of shaving. These are seem- 
ingly trivial things, but they all figure on the debit side of the patient's struggle for health.

Heat and cold, sun, shade and wind currents all markedly affect the thermometric reading. I have seen one and one-half degrees of temperature rise from sitting before an open fire. I have also had some patients whose temperature invariably rose after sleeping in day time. I mention these things to show the need for care in properly interpreting the daily temperature curve.

How often too do we see temperature rises from talking and laughing, something that is most difficult to control, but, nevertheless, demanding at times severe restrictions. I have seen these same temperatures disappear in cases who had throat complications wherein all use of the voice had been interdicted. Of all the certain fever producers, however, and the one that gets physician and patient alike into trouble, is visiting. The pernicious habit of visiting the sick is a custom of great antiquity, but this is about all it has to recommend it. One is almost constrained to say, from our neighbors and friends, Good Lord, deliver us.

Rest is unquestionably our sheet anchor in the treatment' of fever; yet I have repeatedly seen a lingering bed temperature disappear on moderate exercise. Similarly the pulse rate is increased very markedly by exercise, and should be most carefully watched; yet on one occasion I witnessed, in a young man, a sustained average fall of fifteen heart beats per minute after the beginning of exercise, all of which demonstrates the need of more closely individualizing these patients.

I not infrequently take the pulse during and following exercise. Some most interesting things are thus disclosed. One young woman, well nourished, afebrile, was on exercise. Her average pulse rate at rest was 85 . To my utter amazement her pulse on moderate exercise was 160 . It was the only abnormal condition I was ever able to discover. On very slow walking her pulse would be over 130, and on ceasing exercise it would quickly fall to normal. I was never able either to account for it or correct it. The patient has been well for three years. I have seen a markedly irregular pulse in a young man from a game of bridge, never observed at other times. Not infrequently will one see an increase of cough with the initiation of acute constipation. I witnessed on one occasion the disappearance of a most annoying, irritating cough occurring each morning by the use of bed shoes and a hot water bottle to the feet.

The accurate observation of bodily functions is likely the greatest usefulness which the physician derives from the use of some sort of daily clinical chart such as I have devised. The record which is thus kept enables the attending physician to keep closely in touch with the patient's condition with a minimum of expenditure both of time and energy. The quick comparison of temperature curves and of the weight line is of immense advantage over the other forms of clinical sheets.

It is likewise possible to show accurately and graphically the effects of all therapeutic measures used in the care of the case. The smallest temperature reaction from tuberculin, or possibly from an autogenous vaccine, can almost instantly be picked out on such a clinical chart, all of which counts for greater individualization.

In the foregoing I have attempted simply to demonstrate how only a few of the apparently trivial and unusual things affect the welfare of these people. The tuberculous patient merits and deserves more individualizing than he commonly receives. The sanatorium is the ideal place for putting into operation the ideas set forth in this article, but a great deal more could be done by the man in general practice, and in the continuous roll chart, such as I have devised, the physician will find an ally of incalculable assistance in the closer observation of these patients.

\section{RELATION OF GAS EMBOLISM TO THE PRO- DUCTION OF ARTIFICIAL PNEU- MOTHORAX.* \\ By Stevens T. Harris, M.D., Highlands, N. C.}

From all sides come reports of the employment and success of artificial pneumothorax as a treatment of tuberculosis of the lungs. It is safe to say that the results of no other method ever employed can compare with the wonderful results obtained by this procedure. In fact, it is the only real curative treatment for phthisis which has ever been devised. One has but to try it to be convinced.

The afterglow of the tuberculin mirage is beginning to fade. The significance of this statement can be appreciated when it is stated that the United States Army has discarded tuberculin as worthless, and that the immortal dean of American phthisiologists has had artificial pneumo thorax produced on himself.

Surgical procedure has again scored a victory. Artificial pneumothorax, like other surgical methods, has its dangers - the chief among these is

*Read at the Sixth Annual Meeting of the Southern Medical Association, Jacksonville, Fla., Nov. $12-14,-1912$ 